\title{
Cutaneous Malignant Melanoma: A Review of Early Diagnosis and Management
}

\author{
Piyu Parth Naik
}

\begin{abstract}
Cutaneous melanoma (CM) is a malignant tumor formed from pigment-producing cells called melanocytes. It is one of the most aggressive and fatal forms of skin malignancy. In the last decades, CM's incidence has gradually risen, with 351,880 new cases in 2015. Since the 1960s, its incidence has increased steadily, in 2019, with approximately 96,000 new cases. A greater understanding of early diagnosis and management of CM is urgently needed because of the high mortality rates due to metastatic melanoma. Timely detection of melanoma is crucial for successful treatment, but diagnosis with histopathology may also pose a significant challenge to this objective. Early diagnosis and management are essential and contribute to better survival rates of the patient. To better control this malignancy, such information is expected to be particularly useful in the early detection of possible metastatic lesions and the development of new therapeutic approaches. This article reviews the available information on the early diagnosis and management of $\mathrm{CM}$ and discusses such information's potential in facilitating the future prospective.
\end{abstract}

Keywords: Cutaneous melanoma; Malignant melanoma; Early diagnosis; Management; Mortality; Tumor

\section{Introduction}

One of the most aggressive cancers seen in humans is cutaneous melanoma (CM), a tumor formed from melanocytes. Melanocytes originate from the neural crest located along with the choroidal layer of the eye, mucosal surfaces and meninges in the hair follicles and basal epidermis [1]. The incidence of CM continues to rise globally, becoming one of the most common cancers seen in young adults. CM accounts for 3\% of all skin cancers, but $65 \%$ of skin cancer deaths are caused. However, in patients with incipient melanoma, early detection and appropriate treatment of the tumor results in a cure rate of over

Manuscript submitted November 26, 2020, accepted December 23, 2020

Published online February 24, 2021

Department of Dermatology, Saudi German Hospitals and Clinics, Hessa Street 331 West, Al Barsha 3, Exit 36 Sheikh Zayed Road, Opposite of American School, Dubai, United Arab Emirates. Email: drpiyu85@gmail.com

doi: https://doi.org/10.14740/wjon1349
$90 \%$ [2]. CM can occur anywhere on the skin's surface, but its position in a specific section of the body seems to be affected by the sex and age of the patient. In the neck and head region, about $20 \%$ of all tumors have a poorer prognosis than CM at other locations [3].

The development of $\mathrm{CM}$ is the product of the interaction between host and environmental factors, as with all cancers [4]. Ultraviolet radiation (UV) is the most widely recognized environmental risk factor for $\mathrm{CM}$ growth from different sources such as sun and tanning beds. Individuals with lighter skin and hair tone have low melanin levels and are at increased risk of melanoma development. Additionally, the sunburns accumulated since adolescence in individuals are also at high risk. Moreover, the quantity of moles on an individual's body expands the risk of CM [5]. A positive family history of CM is also at an increased risk due to sun exposure habits and/or inherited genetic mutations. $C D K N 2 A$ gene on chromosome 9 in a mutated form in individuals is believed to be at high risk for melanoma development. Studies reported that $70 \%$ of $\mathrm{CM}$ cells had affected the $C D K N 2 A$ gene due to somatic mutations. Under normal circumstances, in cancer suppression, this gene's product plays an important role; this controls the growth of tumor cells; but if this gene mutates, the action of the tumor suppressor is lost and cancer cells can develop uncontrollably [5]. The survival of patients with malignant melanoma is closely associated with early detection. There is no risk of death for melanoma limited to the epidermis (in situ), and there is little chance of metastatic spread from a thin melanoma lesion. Although several factors influence survival, in some studies, tumor thickness is the most important factor [6]. With fundamental behavioral changes, melanoma can be practically preventable. Therefore, even with the emergence of modern methods for the treatment of advanced diseases, in this new century, the focus on prevention in professional and public education and the early identification and management of this tumor is becoming increasingly important. The current review discusses the advancement in approaches towards diagnosis, staging, specific biomarkers associated with melanoma and management strategies with these backgrounds.

\section{Epidemiology}

CM causes mortality in more than $90 \%$ of skin diseases. In a report by the Canadian Cancer Society, about 1,250 Canadians died in 2017 and 7,200 individuals were diagnosed with melanoma. Worldwide, CM has continued to show rates of rising 
Table 1. Classification of Cutaneous Melanoma According to TNM

\begin{tabular}{ll}
$\begin{array}{l}\text { Melanoma } \\
\text { stage }\end{array}$ & Description \\
\hline $\begin{array}{l}\text { ( } \text { in situ) } \\
\text { IA }\end{array}$ & Only the outer or top layer of skin cancer cells. \\
IB & The tumor is $>0.8 \mathrm{~mm}$ but $<1 \mathrm{~mm}$ with possible ulceration or without ulceration; the tumor is $0.8 \mathrm{~mm}$ thick or less. \\
IIA & The tumor, without ulceration, is $>1 \mathrm{~mm}$ but $<2 \mathrm{~mm}$ thick. \\
IIB & The tumor is $>2 \mathrm{~mm}$ thick but $<4 \mathrm{~mm}$ thick without ulceration or with ulceration, the tumor is $>2 \mathrm{~mm}$ thick with ulceration but $<4 \mathrm{~mm}$ thick, or the tumor is $>4 \mathrm{~mm}$ thick without ulceration. \\
IIC & With ulceration, the tumor is more than $4 \mathrm{~mm}$ thick. \\
III & The spread of cancer to one or more lymph nodes close to the initial disease site. \\
IV & Cancer, also called metastatic melanoma, has spread to other body areas, such as the liver and lungs. \\
\hline
\end{tabular}

TNM: tumor-node-metastases.

incidence. It is currently predicted that one in 34 males and one in 53 women will be diagnosed with melanoma during their lives [5]. The overall frequency of $\mathrm{CM}$ has been expanding yearly at a quicker rate than other cancer types. It is ranked the 15 th among the most common cancers worldwide with a growing incidence. The incidence rate of CM differs significantly among countries, and this variation in incidences is attributed to variations in sunlight exposure and differences in the phenotype of skin [5]. The three countries with the highest occurrence rate of CM are European countries, such as Denmark, Sweden and the Netherlands; and the incidence of CM is positively associated with the age group of above 75 years $[7,8]$.

\section{Staging, Subtypes and Pathogenesis}

According to the classification of tumor-node-metastases (TNM), the five stages of CM (0 - IV) were shown in Table 1 [5]. The five disease stages of CM were defined using the following terms: early, locoregional and metastatic. Cancer that has persisted in the primary site and within the skin is called early stages (stages 0 - IIC). Cancer has spread to the skin or lymph nodes (LNs) or lymph vessel areas refer to a locoregional. The cancer is in stage IIII if such a spread has occurred. Cancer that has spread to other body parts and other organs is called "metastatic". In such cases, stage IV of the disease will be considered. Patients diagnosed through biopsy with shallow lesions $(4.0 \mathrm{~mm})$ are correlated with elevated risk for the metastatic stage. If metastasis occurs, patients are given a diagnosis of stage III or IV. The LNs are the most probable noncontiguous regions where CM spreads. Sentinel lymph nodes (SLNs) are specifically crucial because they are the first nodes identified in the area where the primary CM is located [5, 9].

A good indicator of recurrence and survival in patients with CM is the absence or presence of CM cells in the SLN. The common areas for CM metastasis are the subcutaneous tissues and skin. With $10 \%$ of patients developing pulmonary metastasis in the disease, lungs and pleura are the first most common visceral metastasis sites in CM. Another such place for the metastatic spread in CM cases is the brain [5, 9].

In $10-20 \%$ of cases with metastatic CMM, hepatic metastases are found. Skeletal metastasis is uncommonly diagnosed compared to other sites but is still diagnosed in 11-17\% of CM cases. The gastrointestinal spread is diagnosed in later-stage disease, close to skeletal metastasis, with the small intestine being the frequent site. In contrast with men whose CM is found on the trunk, head or neck, women are most commonly diagnosed with $\mathrm{CM}$ on an extremity, which is the crucial explanation for improved overall prognosis. Increased age is associated with a more unsatisfactory outcome. An excellent prognostic factor is the degree of $\mathrm{LN}$ involvement, i.e., a favorable prognosis is inversely proportional to an increased number of nodes and metastasis. A higher mortality rate than spread confined to different locations is often associated with pulmonary, hepatic and brain metastasis. It is necessary to identify the exact location of metastasis, as it determines options for treatment [5].

Amelanotic, desmoplastic, acral lentiginous, nodular, lentigo maligna and superficial spreading are the subtypes of melanoma [10]. The superficial spreading subtype is most commonly found in approximately $70 \%$ of melanomas. The lentigo maligna subtype is less commonly diagnosed; it progresses slowly and seems to be found in areas exposed to sunlight (face, head). The absence of a radial growth phase, robust vertical invasion, and variable presentation define nodular melanomas. In cases with darker skin tone, acral lentiginous melanomas are also associated and are usually found in the subungual spaces, hands and soles. In elderly patients, desmoplastic melanomas are sporadic and are usually observed. Amelanotic melanomas, the most complex diagnostic subtype, have no pigmentation and are very rarely diagnosed [9]. The response rate to treatment decreases to approximately $5-20 \%$ after melanoma spreads or metastasizes from its origin into other cutaneous or subcutaneous tissues, and the 10-year survival rate is only around $10 \%$ [11]. It was challenging to treat metastatic melanoma, showing low cure and survival rates following surgical resection and radiation therapy. Cancer cells have distinctive molecular properties at the cellular level that allow for apoptosis avoidance, infinite growth potential without the need for growth factors, angiogenesis and metastasis. Identifying the specific molecular changes that allow the growth and survival advantage of melanoma cells over others can enable more successful targeted therapies to be developed to improve the prognosis of melanoma patients [12]. 


\section{Early Diagnosis and Its Current Trends}

For the effectiveness of treatment, early detection of lesions is essential. Diagnosis is considered early when, during the stage of radial development, the time in which the neoplastic cells are confined to the epidermis is detected. This is important for lower morbidity-related treatment, a greater chance of cure, and mortality reduction [13]. The melanoma clinical diagnosis is based on morphological criteria analysis and is thus subjective and can be challenging for dermatologists and general practitioners. It is performed by visual examination, aided by lesion dermoscopy. A diagnostic excision is recommended when a lesion is clinically suspected of having melanoma. Skin biopsy remains the initial step to set up an authoritative finding of CM, though different molecular and imaging techniques are also known. For a lesion that is clinically indicative of CM, a complete excision biopsy should be performed, including the entire lesion with negative margins; notice that the lesion is not histologically cut around the deep margin [1416]. This can be accomplished using a restricted fringe edge of 1 - $3 \mathrm{~mm}$ around the skin lesion concerned [14]. A partial biopsy can wrongly stage CM, which may affect the planning of treatment [14, 17-19]. Previously the diagnosis of skin cancer was done by bleeding ulceration, dermoscopy, computer analysis in vivo diagnosis procedures etc. Recently, there has been great interest in developing artificial intelligence (AI)enabled computer-aided diagnostics solutions for the diagnosis of skin cancer $[20,21]$.

A SLN biopsy is routinely performed in cases having tumors more than $1 \mathrm{~mm}$ thickness. Excisional biopsy in various forms such as elliptical, punch, and saucerization is performed; amongst which saucerization being the most common as it is more convenient and time-saving. Saucerization with a superficial shave biopsy should not be confused that is only used when suspected of invasive melanoma. Superficial shave biopsies might misjudge Breslow thickness, ultimately mislabeling CM's stage and are thus not encouraged for diagnosis of CM $[19,22]$. Complete excisional biopsy is difficult to perform in challenging areas, including acral/face surfaces. Under such circumstances, shave, punch or elliptical/fusiform incisional biopsy should be performed [23].

Incisional/partial biopsies have not yet been shown to impact patient outcomes adversely due to the transfer of melanoma cells into blood vessels or cutaneous lymphatics. Incisional vs. excisional biopsy types rarely affect disease recurrence rates or SLN, nor does it result in metastasis [18, 24]. For a suspicious nail lesion (e.g., diffuse pigmentation, melanonychia striata, or amelanotic changes), after the nail matrix is sampled, a biopsy is carried out. Since nail anatomy is complex and melanoma occurs in the nail matrix, professional practitioners better evaluate and sample suspected nail lesions. Prebiopsy photos are of significant help to pathologic/clinical connection and help to forestall medical procedure at an incorrect site if further therapy is required. Due to availability, noninvasive approaches such as optical coherence tomography, gene expression analysis, electrical impedance spectroscopy and reflectance confocal microscopy are more useful [25-27]. To further label melanocytic lesions as malignant or benign, noninvasive genomic methods such as adhesive patch biopsy are also used to predict the need for biopsy testing. The selection of these noninvasive techniques ultimately depends upon clinical utility, the cost versus advantage, and contending methodologies [19]. Several principles and mechanisms are involved in the non-biopsy diagnosis of skin cancer such as optical based, thermography, photodynamic based, sonography and electrical bioimpedance. The optical based mechanism involved, the light is passed inside the tissues of the skin as the light is scattered into the tissues. The change in the property of the reflected light is used for diagnosis. The photodynamic based mechanism involved to detect the presence of tumor cells, a photosensitive marker is introduced into the particular area. The diagnosis of skin cancer performed using sound waves is called sonography. Thermal imaging is based on the phenomenon of electromagnetic radiation being produced by any object with a temperature above absolute zero. Photodynamic based mechanism used to detect the presence of tumor cells into the particular area $[20,28]$.

Despite the significance of early detection to prevent melanoma mortality, little is understood about how patients with the disease will be detected [29]. The probability of melanoma death is causally linked to Breslow's primary lesion thickness, and there is a strong association between the thickness of the tumor and the delay in reporting the lesion as suspicious [30]. Therefore, in predicting the outcome, it is vital to minimize the diagnostic delay, considering the patient's identification and the search for assistance and the doctor's diagnosis and proper evaluation. There are multifactorial reasons for delays in diagnosing patients with signs and symptoms of melanoma, including a lack of regular skin examination by patients and physicians, and a lack of population awareness of the disease. A study by Xavier et al [31] (2016) reported that the patient's critical delay factor was connected. Although there is some difference in other studies, our average delay of 5 months was comparable to patient-related delays of around 2 to 9.8 months previously published $[30,32,33]$. Although the study by Richard et al [34], recorded an average delay of 2 months, the author states that this period is awfully long for this population, as at this time several campaigns were carried out in France. Several studies reported that the patient's delay was demonstrated in Table 2 [30-32, 35-40].

\section{Clinical Characteristics}

\section{Patients history}

During regular skin examination, melanoma lesions are usually detected unintentionally [41]. Occasionally, persistent scratching, bleeding, or crusting of a pigmented lesion may alert patients to the presence of a related nodule. Nevertheless, most melanomas are symptomless and can only induce those mentioned above local inflammatory symptoms after growth progression has occurred [42].

Once a diagnosis is suspected, the past should include questions related to locations of possible metastasis. New-onset back pain, changes in bowel habits, dyspnea, shortness of 


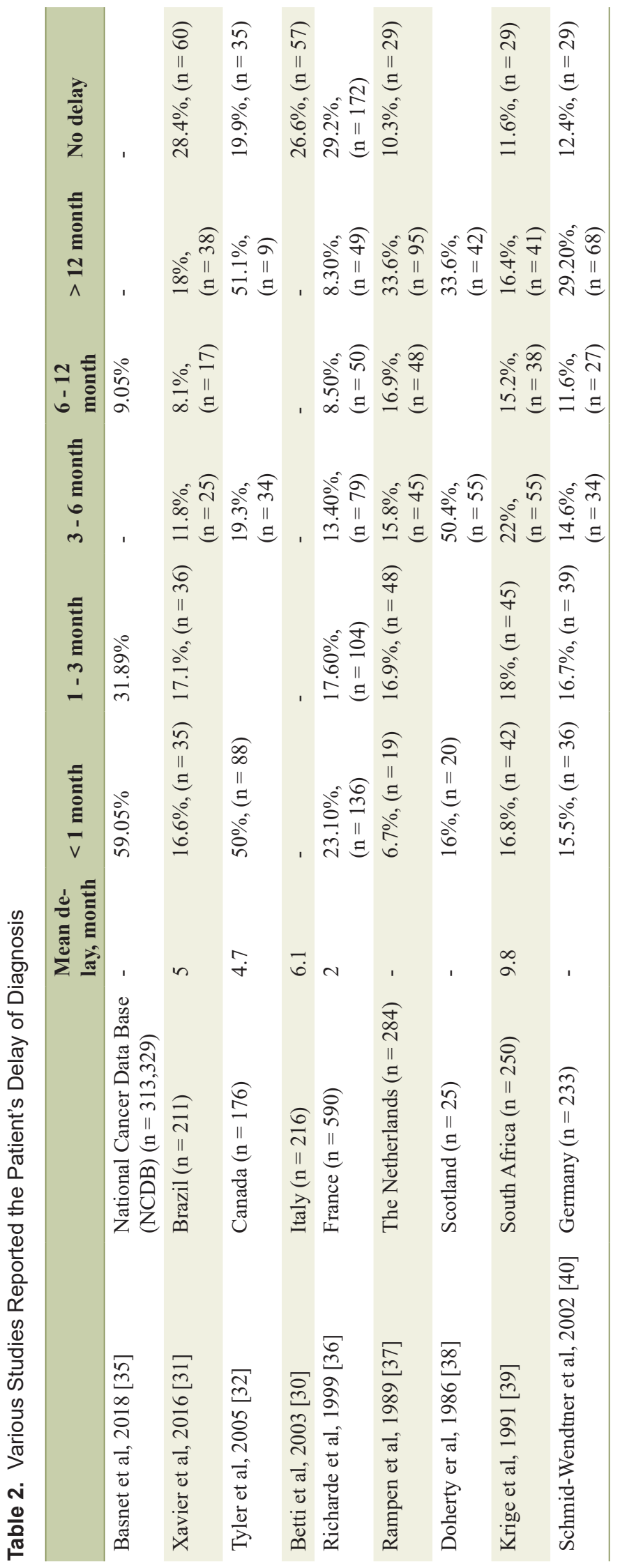

breath, hemoptysis, coughing, vision changes, headaches, seizures and other systemic symptoms (weight loss, night sweats, chills, fever) can be possible indications of metastatic spread [43].

\section{Histologic confirmation}

Routine histologic examination by the receiving department of pathology requires diagnostic confirmation [9]. In an attempt to distinguish benign from malignant melanoma diseases, microscopic observations, including amplified cellularity, cytologic atypia, and it is essential to note the number of dermal mitotic figures.

Formal reporting of Breslow thickness ( $\mathrm{mm}$ ), deep margin status, peripheral margin status, dermal mitotic rate, histologic subtype and the absence and presence of histologic ulceration, pure desmoplasia, neurotropism, vertical growth phase, angiolymphatic invasion, cellular regression, tumor-infiltrating lymphocytes and microsatellitosis is recommended by established guidelines [43].

\section{Disease Types and Prognostic Factors}

Amelanotic, desmoplastic, acral lentiginous, nodular, lentigo maligna, superficial spreading are the main histologic subtypes of melanoma [10]. Stage 0 is known as in situ melanoma, which occurs when microscopically observed tumor cells have not reached the epidermis [44]. The most common form is the superficial spreading subtype and occurs from an existing nevus, comprising approximately $70 \%$ of melanomas recorded. The subtype of lentigo maligna is less prevalent, usually shows gradual development, and mostly occurs in sun-exposed areas. In patients with darker skin pigmentation, Acral lentiginous melanomas have a higher occurrence and occur commonly in subungual spaces, hands and soles. In terms of diagnosis, amelanotic melanomas are the most complicated subtype, have a distinctive pigmentation absence and are considered uncommon [9].

\section{Diagnostic Tools Used for the Early Detection of CM}

The diagnostic tools play a significant role in the early identification of the CM. Several diagnostics tools are used for the early detection of CM were listed in Table 3. Category I instruments including total body photography, sequential digital dermoscopy and dermoscopy are available for patient screening in the everyday clinical routine, meaning that several (if not all) lesions may be checked for a reasonable period. Diagnosis has remained a significant challenge in the face of advancements in diagnostic aids such as dermoscopy, and better methods of precisely diagnosing melanoma are required. Studies have shown that the precise diagnosis of melanoma is challenging even for expert dermoscopists, with one study showing $71 \%$ biopsy sensitivity for melanomas below $6 \mathrm{~mm}$, especially in small diameter lesions [45]. 


\section{Other Technologies}

\section{Thermal imaging}

Compared to normal healthy tissue, the melanoma lesions have more significant metabolic activity, like many other cancers. To evaluate lesions with infrared imaging, using dynamic thermal imaging, this property could be exploited. Early results indicate that melanoma and healthy tissue have detectable temperature differences.

Due to the skin must be cooled to emphasize temperature variations, this approach is presently technically tricky as the sophisticated motion control is important when capturing a thermal image to compensate for the patient's movement [46].

\section{Tissue elastography}

Real-time tissue elastography is an early research technique focused on the premise that milder, normal tissue deforms more quickly than more rigid, malignant tissue. By applying light pressure manually to an ultrasonic transducer, the lesions are measured with simultaneous ultrasonic imaging [46].

\section{Fiber diffraction}

In all mammals, irrespective of age or species, the alpha keratins in hair and nail proteins create a distinctive X-ray fiber diffraction pattern. Like melanoma, some cancers have been shown to cause observable changes in the macromolecules' molecular patterns in nails, skin and hair in recent studies [46].

\section{Noninvasive genomic detection}

An adhesive tape put on suspected lesions to noninvasively sample cells from the stratum corneum is used to collect epidermal genetic information. Using real-time polymerase chain reaction (PCR), cell-isolated RNA is amplified and then hybridized with U133 plus 2.0 GeneChip human genome Affymetrix [47].

\section{Biomarkers Associated With CM}

The recognizable proof of biomarkers that can anticipate persistent advantages towards therapy is a focal objective of disease research. $B-R A F$ proto-oncogene (BRAF) mutations are a standard disease marker in response to RAF inhibitors. After a variable timeframe, these cases develop disease progression and show primary resistance to inhibitors of BRAF. Many researchers have discussed the acquired genetic mutations' role, which affects the signaling pathways and induces resistance to both targeted therapy and chemotherapy in CM [48]. Currently, detecting the mechanisms responsible 
for BRAF and mitogen-activated protein kinase (MEK) inhibitor resistance is not a concern for clinicians; however, it would be more useful to establish noninvasive strategies for determining a tumor's mutation status [49]. A newly developed liquid biopsy helps identify circulating cell-free DNA (cfDNA) derived from melanoma in plasma and serves as a useful blood-based biomarker to detect melanoma's status. Several studies indicate that BRAF kinase inhibitors' response is predicted by $B R A F$-mutated melanoma detection by cfDNA before initiation of treatment. Progression-free survival and lower response rate were found to be correlated with cases with elevated basal cfDNA levels [49, 50]. cfDNA is a predictive tumor burden biomarker, and a rise in cfDNA levels during treatment indicates disease progression and resistance to inhibitor acquisition. Outstandingly, cfDNA helps to mutation detection responsible for resistance to targeted BRAF therapies and can direct us to followup treatment strategies in the future $[49,50]$. The low overall response rate (ORR) has immune checkpoint inhibitors. It was found that programmed cell death protein 1 (PD1) immunohistochemistry assays done on tumor specimens are not markers of choice to determine PD1 inhibitor treatment response due to the heterogeneity in clinical trials [51]. Many other predictive biomarkers are still under investigation. Recently, specific gut microbiota compositions have been found to drive differing responses to immune checkpoint inhibitors in humans $[52,53]$. Several genetic and immunohistochemical markers associated with the diagnosis of CM were summarized in Table 4 [54-79]. This shows that the composition of human gut microbiota modulation could improve the response of immunotherapy. Bioinformatics has yielded promising outcomes in identifying complex biological interactions in different pathways, having a specific role in the immune system. The metabolic, biochemical, and immune-mediated interactions are limited by the computational models and illustrate how they could be involved in melanoma progression $[1,80]$. Therefore, computational methods may also promote the detection of new therapeutic targets and shorten drug discovery [81].

\section{Management}

Mostly, patients who are newly diagnosed with melanoma are at the primitive stage. For these cases, excision is the treatment of choice, and it is the ultimate remedy [82]. Some cases relapse with the disseminated disease; however, $10 \%$ of melanoma cases are diagnosed at an advanced stage and are already metastatic. Amongst cases with stage IV tumors, onethird percent have brain involvement at the time of diagnosis are at a lower likelihood of sustaining the treatment response [83]. For such cases, revolutionization in therapeutic agents occurred since 2011. These agents are BRAF and MEK inhibitors and immune checkpoint inhibitors such as cytotoxic T lymphocyte-associated antigen 4antibodies (CTLA4) and PD1 antibodies. PD1 and CTLA4 antibodies (such as pembrolizumab, ipilimumab, and nivolumab), along with specific BRAF inhibitors (dabrafenib and vemurafenib) alone and/or blended with MEK inhibitors (cobimetinib and trametinib), have the promising outcome [84-90]. Immunotherapy and kinase inhibitors are considered promising therapy, while chemotherapy is considered a second-line treatment option [51]. Several treatment modalities for melanoma metastases were shown in Table 5, and the grades of recommendation were shown in Table 6 [91].

PD1 and CTLA4 antibodies as therapeutic agents offer low response rates with a durable response $[85,89,90]$. In $B R A F$-mutated melanoma, BRAF inhibitors, along with MEK inhibitors, are used as a therapy. The blend has prompted high reaction rates $(70 \%)$ with a quick response rate, along with an advantage of progression-free survival for 1 year [87, 92]. In some $B R A F$-mutated melanoma cases, where BRAF inhibitor resistance has risen, nivolumab and pembrolizumab have shown to be effective $[1,92,93]$.

The aberrant expression of normal testicular proteins has become common knowledge in neoplastically transformed cells over the last decade. A novel family of immunogenic proteins is the cancer testis antigens (CTAs). The genes $L A G E$, $G A G E, B A G E, M A G E$ and NY-ESO-1 code for antigens that autologous, cytolytic CD8 (+) T lymphocytes recognize in different neoplastically transformed cells. One of the most immunogenic antigens ever isolated is the newly identified CTA, NY-ESO-1, which induces spontaneous host immune responses in $50 \%$ of patients with NY-ESO-1-expressing neoplasms [94]. In most cancer forms, NY-ESO-1 is a well-known CTA with re-expression. Recently used NY-ESO-1 in clinical trials was demonstrated in Table 7.

\section{Future Prospective}

Several diagnostic tools, dermoscopy, sequential digital dermoscopy and total body photography are available to identify CM. However, detection has remained a significant challenge amid advancements in diagnostic aids such as dermoscopy, and improved methods of accurately diagnosing melanoma are required. The recent diagnostic tools, including melanoma sniffing dogs, electrical impedance spectroscopy and noninvasive genomic detection, will help detect skin cancer. The combination of PD1/CTLA4with targeted therapy must be considered an experimental approach in recent clinical trials. Interferon- $\alpha$ treatment might be offered to patients with stage II and III melanoma as an adjuvant treatment, as these treatments increase infection-free survival time but disappoint due to toxicity. The consideration of patient attributes (such as lactate dehydrogenase and other biochemical parameters) with toxicity profile, along with comorbidities, and individual patient inclinations are focal components to be considered for cutting edge treatment strategy. Vital cooperation of patients in randomized clinical trials will be of great importance.

Despite potentially promising progress in the treatment of advanced malignant melanoma, prevention and early detection remain the primary priorities in the fight against this disease as we reach the new century. We may minimize the incidence and mortality of malignant melanoma with increased clinical education, public knowledge, patient education, and scientific advancement. As the incidence continues 


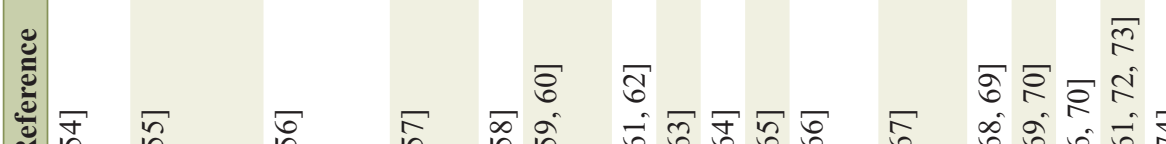

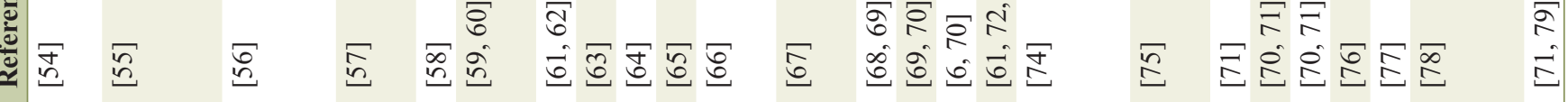


Table 5. Treatment Modalities for Melanoma Metastases

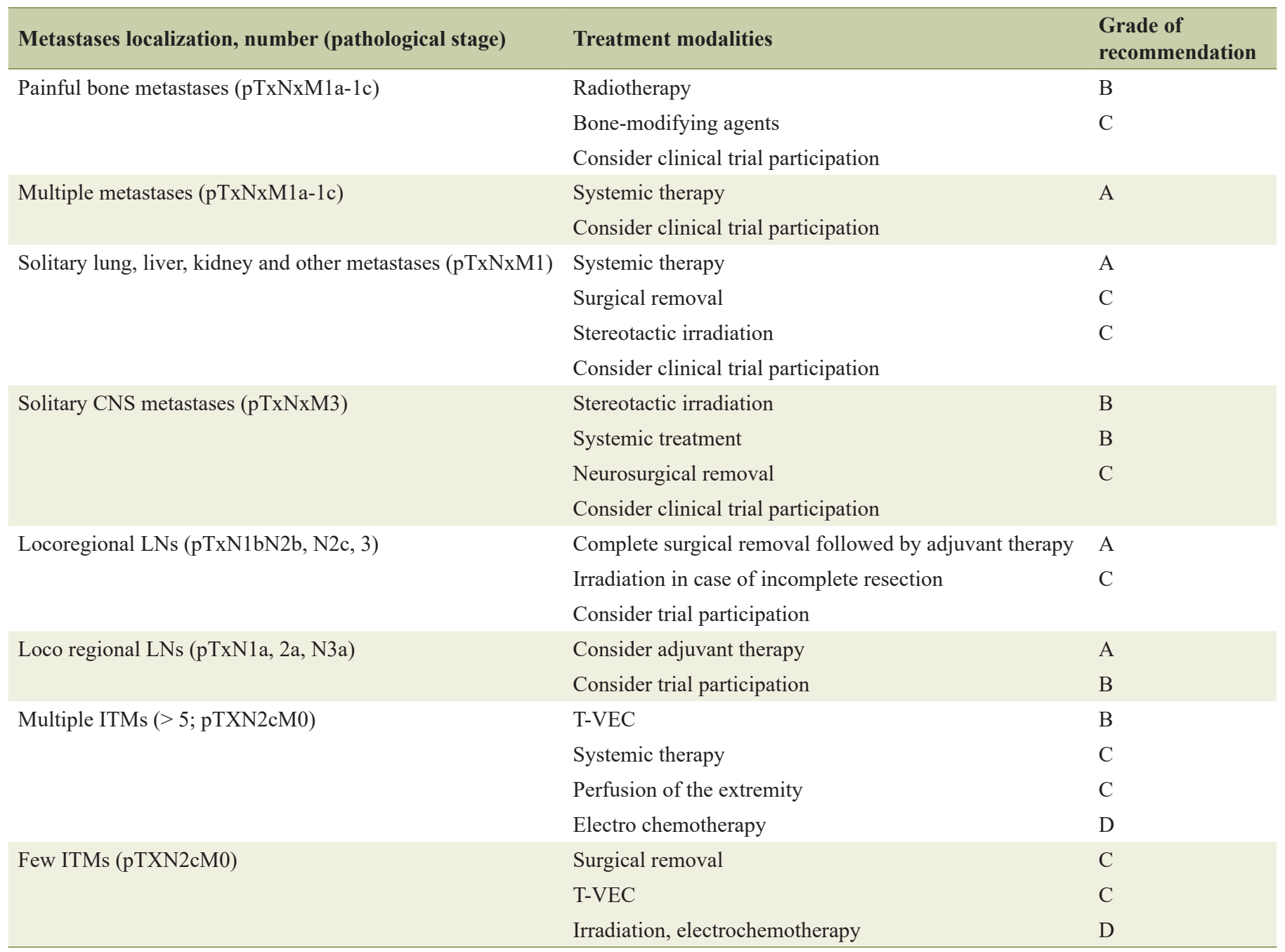

CNS: central nervous system; LNs: lymph nodes; ITMs: in-transit metastases; T-VEC: talimogene laherparepvec.

to increase, a multidisciplinary strategy using those concerned' best expertise is our best defense against this potentially deadly neoplasm.

\section{Conclusions}

The incidence of CM continues to increase globally, and efficient clinical management strategies are necessary to meet this increasing demand. This current review provided valuable information regarding the early diagnosis and management of CM. While the best standard of treatment for melanoma patients is a multidisciplinary approach, surgery remains the best choice for most localized cases. According to rules defined by clinical trials, the disease can be cured by early detection, state of the art biopsy, and sizeable local excision. Eventually, the management of CM depends on the individual patient staging and their response to the therapy.

Table 6. Grades of Recommendation [91]

\begin{tabular}{ll}
\hline Grades & Recommendation \\
\hline A & Strong evidence for efficacy with a substantial clinical benefit, strongly recommended. \\
B & Strong or moderate evidence for efficacy but with a limited clinical benefit, generally recommended. \\
C & Insufficient evidence for efficacy or benefit does not outweigh the risks or disadvantages (adverse events, costs), optional. \\
D & Moderate evidence against efficacy or for adverse outcome, generally not recommended. \\
E & Strong evidence against efficacy or for adverse outcome, never recommended. \\
\hline
\end{tabular}




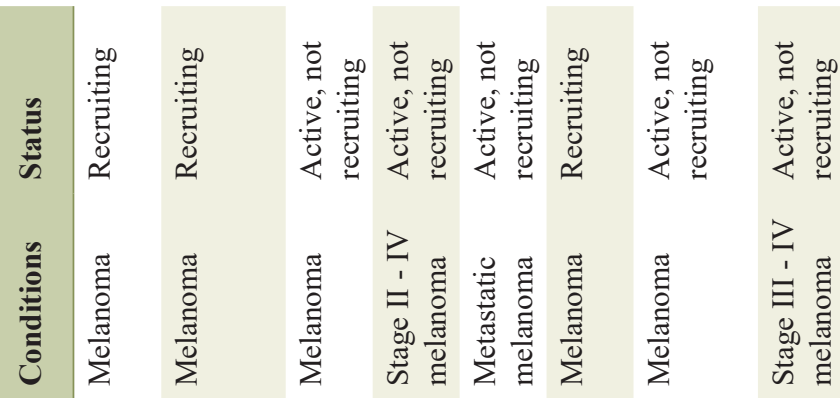

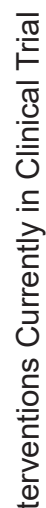

गे

$$
\text { ఖ }
$$

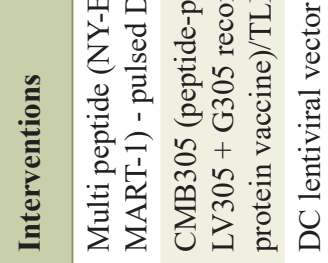

ชิ

훙

芩

퀄

పี ․ㅠ

焉

○े 声

푀류 है

之๐్ ญै

हิे

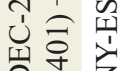

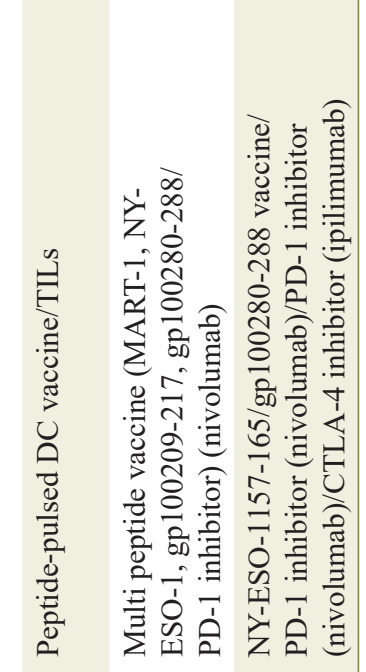

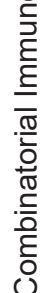
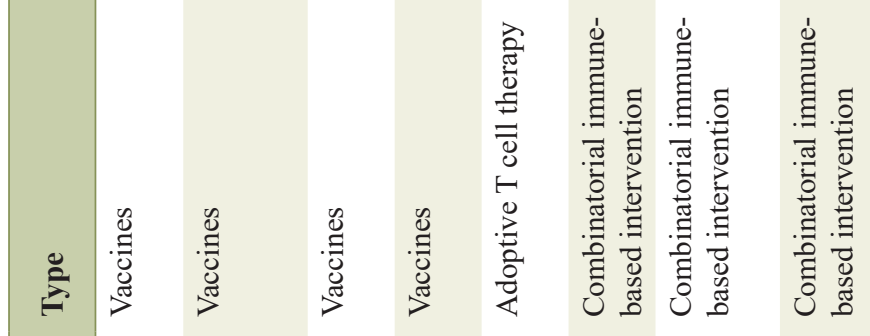

음

ते

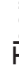

迥

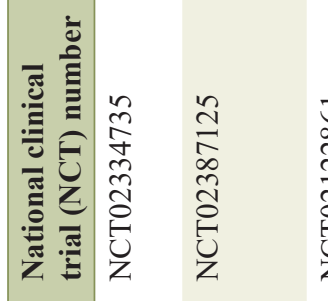

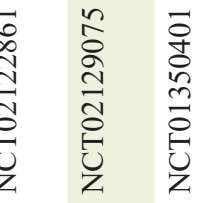

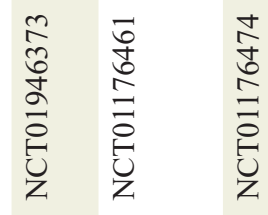

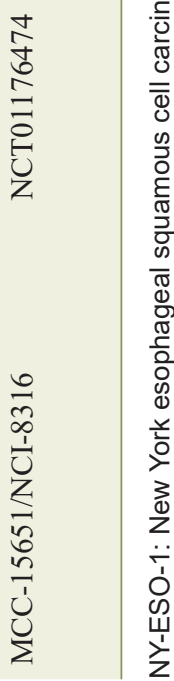

Articles (C) The authors | Journal compilation (CWorld J Oncol and Elmer Press Inc ${ }^{\mathrm{TM}}$ | www.wjon.org 


\section{Acknowledgments}

None to declare.

\section{Financial Disclosure}

This article was self-funded and no other source of funding present.

\section{Conflict of Interest}

None to declare.

\section{Data Availability}

The author declares that data supporting the findings of this study are available within the article.

\section{References}

1. Leonardi GC, Falzone L, Salemi R, Zanghi A, Spandidos DA, McCubrey JA, Candido S, et al. Cutaneous melanoma: From pathogenesis to therapy (Review). Int J Oncol. 2018;52(4):1071-1080.

2. Orzan OA, Sandru A, Jecan CR. Controversies in the diagnosis and treatment of early cutaneous melanoma. J Med Life. 2015;8(2):132-141.

3. Lesage C, Barbe C, Le Clainche A, Lesage FX, Bernard $\mathrm{P}$, Grange F. Sex-related location of head and neck melanoma strongly argues for a major role of sun exposure in cars and photoprotection by hair. J Invest Dermatol. 2013;133(5):1205-1211.

4. Caini S, Gandini S, Sera F, Raimondi S, Fargnoli MC, Boniol M, Armstrong BK. Meta-analysis of risk factors for cutaneous melanoma according to anatomical site and clinico-pathological variant. Eur J Cancer. 2009;45(17):3054-3063.

5. Burns D, George J, Aucoin D, Bower J, Burrell S, Gilbert R, Bower N. The pathogenesis and clinical management of cutaneous melanoma: an evidence-based review. J Med Imaging Radiat Sci. 2019;50(3):460-469 e461.

6. Rigel DS, Carucci JA. Malignant melanoma: prevention, early detection, and treatment in the 21 st century. CA Cancer J Clin. 2000;50(4):215-236; quiz 237-240.

7. The World of Cancer. Sun and skin cancer. https:// theworldofcancer.wordpress.com/category/skin-cancer/. Published 2014.

8. Ward WH FJ. Epidemiology of Melanoma. 2017. https:// www.ncbi.nlm.nih.gov/books/NBK481862/figure/chapter1.f2/?report=objectonly.

9. Kauffmann RM, Chen SL. Workup and staging of malignant melanoma. Surg Clin North Am. 2014;94(5):963972, vii.

10. Markovic SN, Erickson LA, Rao RD, Weenig RH, Pockaj
BA, Bardia A, Vachon CM, et al. Malignant melanoma in the 21st century, part 1: epidemiology, risk factors, screening, prevention, and diagnosis. Mayo Clin Proc. 2007;82(3):364-380.

11. Bhatia S, Tykodi SS, Thompson JA. Treatment of metastatic melanoma: an overview. Oncology (Williston Park). 2009;23(6):488-496.

12. Liu Y, Sheikh MS. Melanoma: Molecular Pathogenesis and Therapeutic Management. Mol Cell Pharmacol. 2014;6(3):228.

13. Garrido AQ, Wainstein AJA, Brandao MPA, de Vasconcellos Santos FA, Bittencourt FV, Ledsham C, Drummond-Lage AP. Diagnosis of cutaneous melanoma: the gap between the knowledge of general practitioners and dermatologists in a Brazilian population. J Cancer Educ. 2020;35(4):819-825.

14. Bichakjian CK, Halpern AC, Johnson TM, Foote Hood A, Grichnik JM, Swetter SM, Tsao H, et al. Guidelines of care for the management of primary cutaneous melanoma. American Academy of Dermatology. J Am Acad Dermatol. 2011;65(5):1032-1047.

15. Hieken TJ, Hernandez-Irizarry R, Boll JM, Jones Coleman JE. Accuracy of diagnostic biopsy for cutaneous melanoma: implications for surgical oncologists. Int J Surg Oncol. 2013;2013:196493.

16. Scolyer RA, Judge MJ, Evans A, Frishberg DP, Prieto VG, Thompson JF, Trotter MJ, et al. Data set for pathology reporting of cutaneous invasive melanoma: recommendations from the international collaboration on cancer reporting (ICCR). Am J Surg Pathol. 2013;37(12):17971814.

17. Karimipour DJ, Schwartz JL, Wang TS, Bichakjian CK, Orringer JS, King AL, Huang CC, et al. Microstaging accuracy after subtotal incisional biopsy of cutaneous melanoma. J Am Acad Dermatol. 2005;52(5):798-802.

18. Mills JK, White I, Diggs B, Fortino J, Vetto JT. Effect of biopsy type on outcomes in the treatment of primary cutaneous melanoma. Am J Surg. 2013;205(5):585-590; discussion 590.

19. Swetter SM, Tsao H, Bichakjian CK, Curiel-Lewandrowski C, Elder DE, Gershenwald JE, Guild V, et al. Guidelines of care for the management of primary cutaneous melanoma. J Am Acad Dermatol. 2019;80(1):208250 .

20. Narayanamurthy V, Padmapriya P, Noorasafrin A, Pooja B, Hema K, Firus Khan AY, Nithyakalyani K, et al. Skin cancer detection using noninvasive techniques. RSC Adv. 2018;8(49):28095-28130.

21. Goyal M, Knackstedt T, Yan S, Hassanpour S. Artificial intelligence-based image classification methods for diagnosis of skin cancer: Challenges and opportunities. Comput Biol Med. 2020;127:104065.

22. Kaiser S, Vassell R, Pinckney RG, Holmes TE, James TA. Clinical impact of biopsy method on the quality of surgical management in melanoma. J Surg Oncol. 2014;109(8):775-779.

23. Ng JC, Swain S, Dowling JP, Wolfe R, Simpson P, Kelly JW. The impact of partial biopsy on histopathologic diagnosis of cutaneous melanoma: experience of an Australian 
tertiary referral service. Arch Dermatol. 2010;146(3):234239.

24. Bong JL, Herd RM, Hunter JA. Incisional biopsy and melanoma prognosis. J Am Acad Dermatol. 2002;46(5):690694.

25. Rajpara SM, Botello AP, Townend J, Ormerod AD. Systematic review of dermoscopy and digital dermoscopy/ artificial intelligence for the diagnosis of melanoma. Br J Dermatol. 2009;161(3):591-604.

26. Pezzini C, Kaleci S, Chester J, Farnetani F, Longo C, Pellacani G. Reflectance confocal microscopy diagnostic accuracy for malignant melanoma in different clinical settings: systematic review and meta-analysis. J Eur Acad Dermatol Venereol. 2020;34(10):2268-2279.

27. Stevenson AD, Mickan S, Mallett S, Ayya M. Systematic review of diagnostic accuracy of reflectance confocal microscopy for melanoma diagnosis in patients with clinically equivocal skin lesions. Dermatol Pract Concept. 2013;3(4):19-27.

28. Parsons SK, Chan JA, Yu WW, Obadan N, Ratichek SJ, Lee J, Sen S, et al.: In: Noninvasive Diagnostic Techniques for the Detection of Skin Cancers. Rockville (MD), 2011.

29. Brady MS, Oliveria SA, Christos PJ, Berwick M, Coit DG, Katz J, Halpern AC. Patterns of detection in patients with cutaneous melanoma: implications for secondary prevention. Cancer Interdiscip Int $\mathrm{J}$ Am Cancer Soc. 2000;89(2):342-347.

30. Betti R, Vergani R, Tolomio E, Santambrogio R, Crosti C. Factors of delay in the diagnosis of melanoma. Eur J Dermatol. 2003;13(2):183-188.

31. Xavier MH, Drummond-Lage AP, Baeta C, Rocha L, Almeida AM, Wainstein AJ. Delay in cutaneous melanoma diagnosis: Sequence analyses from suspicion to diagnosis in 211 patients. Medicine (Baltimore). 2016;95(31):e4396.

32. Tyler I, Rivers JK, Shoveller JA, Blum A. Melanoma detection in British Columbia, Canada. J Am Acad Dermatol. 2005;52(1):48-54.

33. Richard MA, Grob JJ, Avril MF, Delaunay M, Gouvernet J, Wolkenstein P, Souteyrand P, et al. Delays in diagnosis and melanoma prognosis (II): the role of doctors. Int J Cancer. 2000;89(3):280-285.

34. Richard MA, Grob JJ, Avril MF, Delaunay M, Gouvernet J, Wolkenstein P, Souteyrand P, et al. Delays in diagnosis and melanoma prognosis (I): the role of patients. Int J Cancer. 2000;89(3):271-279.

35. Basnet A, Wang D, Sinha S, Sivapiragasam A. Effect of a delay in definitive surgery in melanoma on overall survival: A NCDB analysis. J Clin Oncol. 2018;36(15 suppl):e21586-e21586.

36. Richard MA, Grob JJ, Avril MF, Delaunay M, Thirion X, Wolkenstein P, Souteyrand P, et al. Melanoma and tumor thickness: challenges of early diagnosis. Arch Dermatol. 1999;135(3):269-274.

37. Rampen FH, Rumke P, Hart AA. Patients' and doctors' delay in the diagnosis and treatment of cutaneous melanoma. Eur J Surg Oncol. 1989;15(2):143-148.

38. Doherty VR, MacKie RM. Reasons for poor prognosis in
British patients with cutaneous malignant melanoma. $\mathrm{Br}$ Med J (Clin Res Ed). 1986;292(6526):987-989.

39. Krige JE, Isaacs S, Hudson DA, King HS, Strover RM, Johnson CA. Delay in the diagnosis of cutaneous malignant melanoma. A prospective study in 250 patients. Cancer. 1991;68(9):2064-2068.

40. Schmid-Wendtner MH, Baumert J, Stange J, Volkenandt M. Delay in the diagnosis of cutaneous melanoma: an analysis of 233 patients. Melanoma Res. 2002;12(4):389394.

41. Aitken JF, Elwood M, Baade PD, Youl P, English D. Clinical whole-body skin examination reduces the incidence of thick melanomas. Int J Cancer. 2010;126(2):450-458.

42. Psaty EL, Scope A, Halpern AC, Marghoob AA. Defining the patient at high risk for melanoma. Int J Dermatol. 2010;49(4):362-376.

43. Coit DG, Andtbacka R, Anker CJ, Bichakjian CK, Carson WE, 3rd, Daud A, Dimaio D, et al. Melanoma, version 2.2013: featured updates to the NCCN guidelines. J Natl Compr Canc Netw. 2013;11(4):395-407.

44. Edge SB, Byrd DR, Carducci MA, Compton CC, Fritz AG, Greene FL. AJCC Cancer Staging Manual (Vol 7). Springer New York; 2010. https://www.eyecancercure. com/content/documents/csmanual.pdf.

45. Friedman RJ, Gutkowicz-Krusin D, Farber MJ, Warycha M, Schneider-Kels L, Papastathis N, Mihm MC, Jr., et al. The diagnostic performance of expert dermoscopists vs a computer-vision system on small-diameter melanomas. Arch Dermatol. 2008;144(4):476-482.

46. Ferris LK, Harris RJ. New diagnostic aids for melanoma. Dermatol Clin. 2012;30(3):535-545.

47. Wachsman W, Morhenn V, Palmer T, Walls L, Hata T, Zalla J, Scheinberg R, et al. Noninvasive genomic detection of melanoma. Br J Dermatol. 2011;164(4):797-806.

48. Steelman LS, Chappell WH, Abrams SL, Kempf RC, Long J, Laidler P, Mijatovic S, et al. Roles of the Raf/ MEK/ERK and PI3K/PTEN/Akt/mTOR pathways in controlling growth and sensitivity to therapy-implications for cancer and aging. Aging (Albany NY). 2011;3(3):192222.

49. Gray ES, Rizos H, Reid AL, Boyd SC, Pereira MR, Lo J, Tembe V, et al. Circulating tumor DNA to monitor treatment response and detect acquired resistance in patients with metastatic melanoma. Oncotarget. 2015;6(39):42008-42018.

50. Girotti MR, Gremel G, Lee R, Galvani E, Rothwell D, Viros A, Mandal AK, et al. Application of sequencing, liquid biopsies, and patient-derived xenografts for personalized medicine in melanoma. Cancer Discov. 2016;6(3):286299.

51. Akiyama Y, Nonomura C, Kondou R, Miyata H, Ashizawa T, Maeda C, Mitsuya K, et al. Immunological effects of the anti-programmed death-1 antibody on human peripheral blood mononuclear cells. Int J Oncol. 2016;49(3):1099-1107.

52. Gopalakrishnan V, Spencer CN, Nezi L, Reuben A, Andrews MC, Karpinets TV, Prieto PA, et al. Gut microbiome modulates response to anti-PD-1 immunotherapy in melanoma patients. Science. 2018;359(6371):97-103. 
53. Routy B, Le Chatelier E, Derosa L, Duong CPM, Alou MT, Daillere R, Fluckiger A, et al. Gut microbiome influences efficacy of PD-1-based immunotherapy against epithelial tumors. Science. 2018;359(6371):91-97.

54. Bauer J, Bastian BC. Distinguishing melanocytic nevi from melanoma by DNA copy number changes: comparative genomic hybridization as a research and diagnostic tool. Dermatol Ther. 2006;19(1):40-49.

55. Trolet J, Hupe P, Huon I, Lebigot I, Decraene C, Delattre $\mathrm{O}$, Sastre-Garau X, et al. Genomic profiling and identification of high-risk uveal melanoma by array CGH analysis of primary tumors and liver metastases. Invest Ophthalmol Vis Sci. 2009;50(6):2572-2580.

56. Schouten JP, McElgunn CJ, Waaijer R, Zwijnenburg D, Diepvens F, Pals G. Relative quantification of 40 nucleic acid sequences by multiplex ligation-dependent probe amplification. Nucleic Acids Res. 2002;30(12):e57.

57. Gerami P, Jewell SS, Morrison LE, Blondin B, Schulz J, Ruffalo T, Matushek Pt, et al. Fluorescence in situ hybridization (FISH) as an ancillary diagnostic tool in the diagnosis of melanoma. Am J Surg Pathol. 2009;33(8):11461156.

58. Ribe A, McNutt NS. S100A6 protein expression is different in Spitz nevi and melanomas. Mod Pathol. 2003;16(5):505-511.

59. Niemann TH, Argenyi ZB. Immunohistochemical study of Spitz nevi and malignant melanoma with use of antibody to proliferating cell nuclear antigen. Am J Dermatopathol. 1993;15(5):441-445.

60. Ohsie SJ, Sarantopoulos GP, Cochran AJ, Binder SW. Immunohistochemical characteristics of melanoma. J Cutan Pathol. 2008;35(5):433-444.

61. Carlson JA, Ross JS, Slominski A, Linette G, Mysliborski J, Hill J, Mihm M, Jr. Molecular diagnostics in melanoma. J Am Acad Dermatol. 2005;52(5):743-775; quiz 775748.

62. Scholzen T, Gerdes J. The Ki-67 protein: from the known and the unknown. J Cell Physiol. 2000;182(3):311-322.

63. Bullani RR, Huard B, Viard-Leveugle I, Byers HR, Irmler M, Saurat JH, Tschopp J, et al. Selective expression of FLIP in malignant melanocytic skin lesions. J Invest Dermatol. 2001;117(2):360-364.

64. van den Oord JJ, Maes A, Stas M, Nuyts J, Battocchio S, Kasran A, Garmyn M, et al. CD40 is a prognostic marker in primary cutaneous malignant melanoma. Am J Pathol. 1996;149(6):1953-1961.

65. Van den Oord JJ. Expression of CD26/dipeptidyl-peptidase IV in benign and malignant pigment-cell lesions of the skin. Br J Dermatol. 1998;138(4):615-621.

66. Luftl M, Schuler G, Jungbluth AA. Melanoma or not? Cancer testis antigens may help. Br J Dermatol. 2004;151(6):1213-1218.

67. Li Q, Murphy M, Ross J, Sheehan C, Carlson JA. Skp2 and p27kip1 expression in melanocytic nevi and melanoma: an inverse relationship. J Cutan Pathol. 2004;31(10):633642.

68. Karim RZ, Li W, Sanki A, Colman MH, Yang YH, Thompson JF, Scolyer RA. Reduced p16 and increased cyclin $\mathrm{D} 1$ and $\mathrm{pRb}$ expression are correlated with pro- gression in cutaneous melanocytic tumors. Int J Surg Pathol. 2009;17(5):361-367.

69. Stefanaki C, Stefanaki K, Antoniou C, Argyrakos T, Stratigos A, Patereli A, Katsambas A. G1 cell cycle regulators in congenital melanocytic nevi. Comparison with acquired nevi and melanomas. J Cutan Pathol. 2008;35(9):799808.

70. Tran TA, Ross JS, Carlson JA, Mihm MC, Jr. Mitotic cyclins and cyclin-dependent kinases in melanocytic lesions. Hum Pathol. 1998;29(10):1085-1090.

71. Alonso SR, Ortiz P, Pollan M, Perez-Gomez B, Sanchez L, Acuna MJ, Pajares R, et al. Progression in cutaneous malignant melanoma is associated with distinct expression profiles: a tissue microarray-based study. Am J Pathol. 2004;164(1):193-203.

72. Hilliard NJ, Krahl D, Sellheyer K. p16 expression differentiates between desmoplastic Spitz nevus and desmoplastic melanoma. J Cutan Pathol. 2009;36(7):753-759.

73. Al Dhaybi R, Agoumi M, Gagne I, McCuaig C, Powell J, Kokta V. p16 expression: a marker of differentiation between childhood malignant melanomas and Spitz nevi. J Am Acad Dermatol. 2011;65(2):357-363.

74. Polsky D, Melzer K, Hazan C, Panageas KS, Busam K, Drobnjak M, Kamino H, et al. HDM2 protein overexpression and prognosis in primary malignant melanoma. J Natl Cancer Inst. 2002;94(23):1803-1806.

75. Korabiowska M, Betke H, Kellner S, Stachura J, Schauer A. Differential expression of growth arrest, DNA damage genes and tumour suppressor gene p53 in naevi and malignant melanomas. Anticancer Res. 1997;17(5A):36973700 .

76. Kuzbicki L, Aladowicz E, Chwirot BW. Cyclin-dependent kinase 2 expression in human melanomas and benign melanocytic skin lesions. Melanoma Res. 2006;16(5):435444.

77. Zhuang L, Lee CS, Scolyer RA, McCarthy SW, Zhang XD, Thompson JF, Hersey P. Mcl-1, Bcl-XL and Stat3 expression are associated with progression of melanoma whereas Bcl-2, AP-2 and MITF levels decrease during progression of melanoma. Mod Pathol. 2007;20(4):416-426.

78. Florenes VA, Maelandsmo GM, Holm R, Reich R, Lazarovici P, Davidson B. Expression of activated TrkA protein in melanocytic tumors: relationship to cell proliferation and clinical outcome. Am J Clin Pathol. 2004;122(3):412-420.

79. Slipicevic A, Holm R, Nguyen MT, Bohler PJ, Davidson B, Florenes VA. Expression of activated Akt and PTEN in malignant melanomas: relationship with clinical outcome. Am J Clin Pathol. 2005;124(4):528-536.

80. Pappalardo F, Russo G, Candido S, Pennisi M, Cavalieri S, Motta S, McCubrey JA, et al. Computational modeling of PI3K/AKT and MAPK signaling pathways in melanoma cancer. PLoS One. 2016;11(3):e0152104.

81. Algazi AP, Soon CW, Daud AI. Treatment of cutaneous melanoma: current approaches and future prospects. Cancer Manag Res. 2010;2:197-211.

82. Ross MI, Gershenwald JE. Evidence-based treatment of early-stage melanoma. J Surg Oncol. 2011;104(4):341353. 
83. Luke JJ, Flaherty KT, Ribas A, Long GV. Targeted agents and immunotherapies: optimizing outcomes in melanoma. Nat Rev Clin Oncol. 2017;14(8):463-482.

84. Delyon J, Mateus C, Lefeuvre D, Lanoy E, Zitvogel L, Chaput N, Roy S, et al. Experience in daily practice with ipilimumab for the treatment of patients with metastatic melanoma: an early increase in lymphocyte and eosinophil counts is associated with improved survival. Ann Oncol. 2013;24(6):1697-1703.

85. Hodi FS, O'Day SJ, McDermott DF, Weber RW, Sosman JA, Haanen JB, Gonzalez R, et al. Improved survival with ipilimumab in patients with metastatic melanoma. N Engl J Med. 2010;363(8):711-723.

86. McArthur GA, Chapman PB, Robert C, Larkin J, Haanen JB, Dummer R, Ribas A, et al. Safety and efficacy of vemurafenib in BRAF(V600E) and BRAF(V600K) mutation-positive melanoma (BRIM-3): extended follow-up of a phase 3, randomised, open-label study. Lancet Oncol. 2014;15(3):323-332.

87. Long GV, Stroyakovskiy D, Gogas H, Levchenko E, de Braud F, Larkin J, Garbe C, et al. Dabrafenib and trametinib versus dabrafenib and placebo for Val600 BRAFmutant melanoma: a multicentre, double-blind, phase 3 randomised controlled trial. Lancet. 2015;386(9992):444451.

88. Hamid O, Puzanov I, Dummer R, Schachter J, Daud A, Schadendorf D, Blank C, et al. Final analysis of a randomised trial comparing pembrolizumab versus investigator-choice chemotherapy for ipilimumab-refractory advanced melanoma. Eur J Cancer. 2017;86:37-45.

89. Ribas A, Puzanov I, Dummer R, Schadendorf D, Hamid O, Robert C, Hodi FS, et al. Pembrolizumab versus investigator-choice chemotherapy for ipilimumab-refractory melanoma (KEYNOTE-002): a randomised, controlled, phase 2 trial. Lancet Oncol. 2015;16(8):908-918.

90. Weber JS, D'Angelo SP, Minor D, Hodi FS, Gutzmer R, Neyns B, Hoeller C, et al. Nivolumab versus chemotherapy in patients with advanced melanoma who progressed after anti-CTLA-4 treatment (CheckMate 037): a randomised, controlled, open-label, phase 3 trial. Lancet Oncol. 2015;16(4):375-384.

91. Michielin O, van Akkooi ACJ, Ascierto PA, Dummer $\mathrm{R}$, Keilholz U, the ESMO Guidelines Committee. $\mathrm{Cu}-$ taneous melanoma: ESMO Clinical Practice Guidelines for diagnosis, treatment and follow-up. Ann Oncol. 2019;30(12):1884-1901.

92. Robert C, Schachter J, Long GV, Arance A, Grob JJ, Mortier L, Daud A, et al. Pembrolizumab versus ipilimumab in advanced melanoma. N Engl J Med. 2015;372(26):25212532.

93. Wang J, Chmielowski B, Pellissier J, Xu R, Stevinson K, Liu FX. Cost-effectiveness of pembrolizumab versus ipilimumab in ipilimumab-naive patients with advanced melanoma in the United States. J Manag Care Spec Pharm. 2017;23(2):184-194.

94. Bodey B. Cancer-testis antigens: promising targets for antigen directed antineoplastic immunotherapy. Expert Opin Biol Ther. 2002;2(6):577-584. 